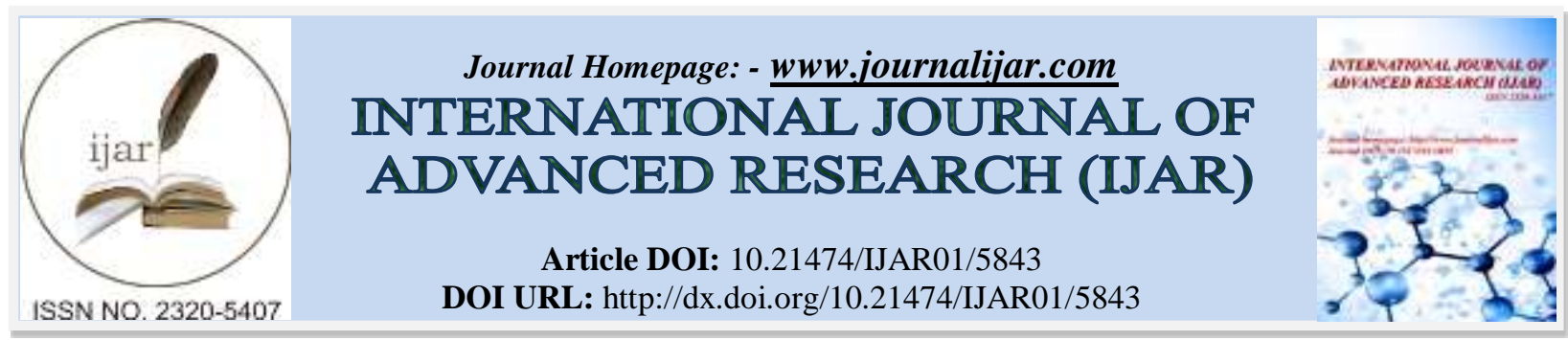

RESEARCH ARTICLE

\title{
A STUDY OF COMPLICATIONS ENCOUNTERED IN PATIENTS UNDERGOING HEMODIALYSIS PROCEDURE.
}

Syed Marghoob Hasan ${ }^{1}$, Himanshu Devender Kumar ${ }^{1}$, P K Prasher ${ }^{1}$ and Richa Goel ${ }^{2}$.

1. Department of Medicine, Maharishi Markandeshwar Institute of Medical Sciences and Research, Mullana, Haryana, India 133207.

2. Department of Biochemistry, Maharishi Markandeshwar Institute of Medical Sciences and Research, Mullana, Haryana, India 133207.

\section{Manuscript Info}

(n........................

Manuscript History

Received: 12 September 2017

Final Accepted: 14 October 2017

Published: November 2017

Keywords:-

Chronic Kidney Disease, Acute Renal

Failure, Hemodialysis, End Stage Renal

Disease.
Abstract

Objective: Hemodialysis is used in the patients with acute or irreversible renal failure, fluid and electrolyte imbalances and end-stage renal disease (ESRD). The patients on hemodialysis are more likely to have cerebrovascular disease, cardiovascular disease and perivascular disease and chronic obstructive pulmonary disease but intra-dialysis complications are frequently encountered. This study was planned to study the occurrence of various complications during hemodialysis procedure.

Research design and methods: Seven hundred forty patients on hemodialysis were studied for complications during hemodialysis. Patients were selected via purposive sampling technique and detailed history and appropriate clinical examination was done in each patient. Complications encountered were divided into three groups: patientrelated complication, technical complications, and vascular accessrelated complications. Data was compiled and appropriate statistical analysis was done.

Results: Most common group of complications found in the study was patient-related complications (63\%) and among that hypotension $(26.8 \%)$ is the commonest followed by headache $(25.1 \%)$ and hypertension $(24.7 \%)$, frequency of vascular access-related complications (4.4\%) and technical complications $(3.1 \%)$ was very low.

Conclusions: Hemodialysis is associated with a vivid number of complications some are even life-threatening, however strict monitoring proper assessment of patients and good clinical acumen may help in early detection and early management without the termination of life-saving procedures.

Copy Right, IJAR, 2017,. All rights reserved.

\section{Introduction:-}

A disruption in kidney function through any cause hampers the ability of the body to maintain body fluid, electrolyte, and acid-base balance.(Arroyo, 2008) Reduced renal function disrupts erythropoietin and prostaglandin synthesis. Hemodialysis is used for patients with acute or irreversible chronic kidney disease and patient with fluid 
and electrolyte imbalances. The lives of many patients with ESRD are prolonged with relief of symptoms if hemodialysis is done at right or appropriate time when needed.

Hemodialysis is a life-saving procedure routinely done for ESRD for the last 35 years.(1) The patients who require hemodialysis are more likely to have cerebrovascular disease, cardiovascular disease and perivascular disease and chronic obstructive pulmonary disease. Hemodialysis is a safe procedure with an estimated death of 1 in total 75000 treatments occurs due to the technical error. However, there are numerous complications which are related to hemodialysis, some of them are life-threatening.(Prabhakar, Singh, Singh, Rathore, \& Choudhary, 2015)

The frequency and severity of the complications usually depend upon the underlying condition of patients who are going for hemodialysis such as diabetes mellitus, coronary artery disease, hypertension, congestive cardiac failure and the patient's degree of compliance with a complex medical regimen. Allergic reaction to dialyzer membranes, sterilizing and reprocessing agents and contaminated dialysate related complications were very common in early days of hemodialysis.(Davenport, 2006)

Materials and method

The present study was conducted in the Department of Medicine at M.M. Institute of Medical Sciences and Research, Mullana, Haryana. Seven hundred forty patients undergoing hemodialysis at dialysis unit due to acute kidney injury (AKI), chronic kidney disease (CKD), acid-base balance, or any other cause were included in the study after informed and written consent. Patients were selected via purposive sampling method. There were no exclusion criteria. All patients were subjected to detailed history, clinical examination and appropriate biochemical evaluation. Complications encountered were divided into three groups: patient-related complication, technical complications, and vascular access-related complications. Appropriate management was provided to the patients whenever complication occurred. The approval of study was obtained from the Institutional Ethical Committee. Data was compiled and appropriate statistical analysis was done.

Complications were grouped into three categories:

\begin{tabular}{|c|c|c|}
\hline $\begin{array}{l}\text { Group } 1 \\
\text { Patient-related Complications }\end{array}$ & $\begin{array}{l}\text { Group } 2 \\
\text { Technical Complication }\end{array}$ & $\begin{array}{l}\text { Group } 3 \\
\text { Vascular } \\
\text { Complications }\end{array}$ \\
\hline 1. Hypotension $(<80 \mathrm{~mm}$ of $\mathrm{Hg})$ & $\begin{array}{ll}\text { 1. } & \begin{array}{l}\text { Heparin-induced } \\
\text { thrombocytopenia }\end{array} \\
\end{array}$ & 1. AV Fistula induced \\
\hline 2. Hypertension (>140 $\mathrm{mm}$ of $\mathrm{Hg})$ & 2. Bleeding diathesis & A. Arterio-Venous Stenosis \\
\hline 3. Nausea & 3. Hemolysis & B. Thrombosis \\
\hline 4. Vomiting & 4. Neutropenia & C. Aneurysm \\
\hline 5. Muscle cramp & 5. Power failure & D. Low dialysis blood flow \\
\hline 6. $\quad$ Itching & 6. Air embolism & E. High flow rate in fistula \\
\hline 7. Fever $\left(>38^{\circ} \mathrm{C}\right)$ & 7. Exsanguinations & F. $\quad$ Steal Syndrome \\
\hline 8. Chills/Shivering & 8. Blood clots in dialyzer & a) Pain \\
\hline 9. Headache & 9. $\quad$ Electrolyte disorder & Pallor \\
\hline 10. Chest pain & 10. Dialyzer reaction & Necrosis \\
\hline 11. Pericarditis & $\begin{array}{l}\text { A. Type A } \quad \text { immediate } \\
\text { Anaphylactic reaction }\end{array}$ & Diminished Plus \\
\hline 12. Cardiac arrhythmia & B. Type B after 15-30 minutes & Develop during catheter placing \\
\hline 13. Myocardial infarction & & a) Cardiac Arrhythmia \\
\hline 14. Sudden cardiac death & & Pneumothorax \\
\hline 15. Cerebral Hemorrhage & & $\begin{array}{ll}\text { c) } & \begin{array}{l}\text { Pleural or mediastinal } \\
\text { hematoma }\end{array}\end{array}$ \\
\hline 16. Stroke & & Air embolism \\
\hline $\begin{array}{ll}\text { 17. Dialysis } & \text { disequilibrium } \\
\text { syndrome } & \\
\end{array}$ & & $\begin{array}{l}\text { e) Nerve injury in neck or } \\
\text { thorax }\end{array}$ \\
\hline a) Irritability & & $\begin{array}{l}\text { f) Carotid Artery Puncture and } \\
\text { Hematoma }\end{array}$ \\
\hline b) Restlessness & & g) Thrombus formation \\
\hline c) Headache & & Infection \\
\hline
\end{tabular}




\begin{tabular}{|l|l|l|}
\hline d) Seizure & & $\begin{array}{l}\text { Central vein thrombosis \& } \\
\text { Stenosis }\end{array}$ \\
\hline e) Blurred vision & & 4. Cardiac arrest \\
\hline f) $\begin{array}{l}\text { Muscle twitching and } \\
\text { fasciculation's }\end{array}$ & & \\
\hline g) Delirium & & \\
\hline h) Backache & & \\
\hline i) $\quad$ Fall in $\mathrm{SPO}_{2}$ & & \\
\hline
\end{tabular}

\section{Results:-}

Mean age in our study was $46.4 \pm 13.8$ years with predominantly males $(69.8 \%) .92 .6 \%$ patients were diagnosed with chronic kidney disease, $7.2 \%$ were of acute kidney injury and $0.1 \%$ were undergoing hemodialysis due to other causes. Only $23 \%$ of the patients had AV fistula as vascular access, rest were provided femoral access. $64.9 \%$ $(\mathrm{N}=480)$ of the subjects faced one or more mentioned complications while $35.1 \%$ ( $\mathrm{N}=260)$ patients had an uncomplicated procedure. Among patients who had complications, $96.25 \%$ ( $\mathrm{N}=226$ out of 260) developed only single complication while $3.75 \%$ ( $\mathrm{N}=34$ out of 260 ) had more than two complications (Fig 1).

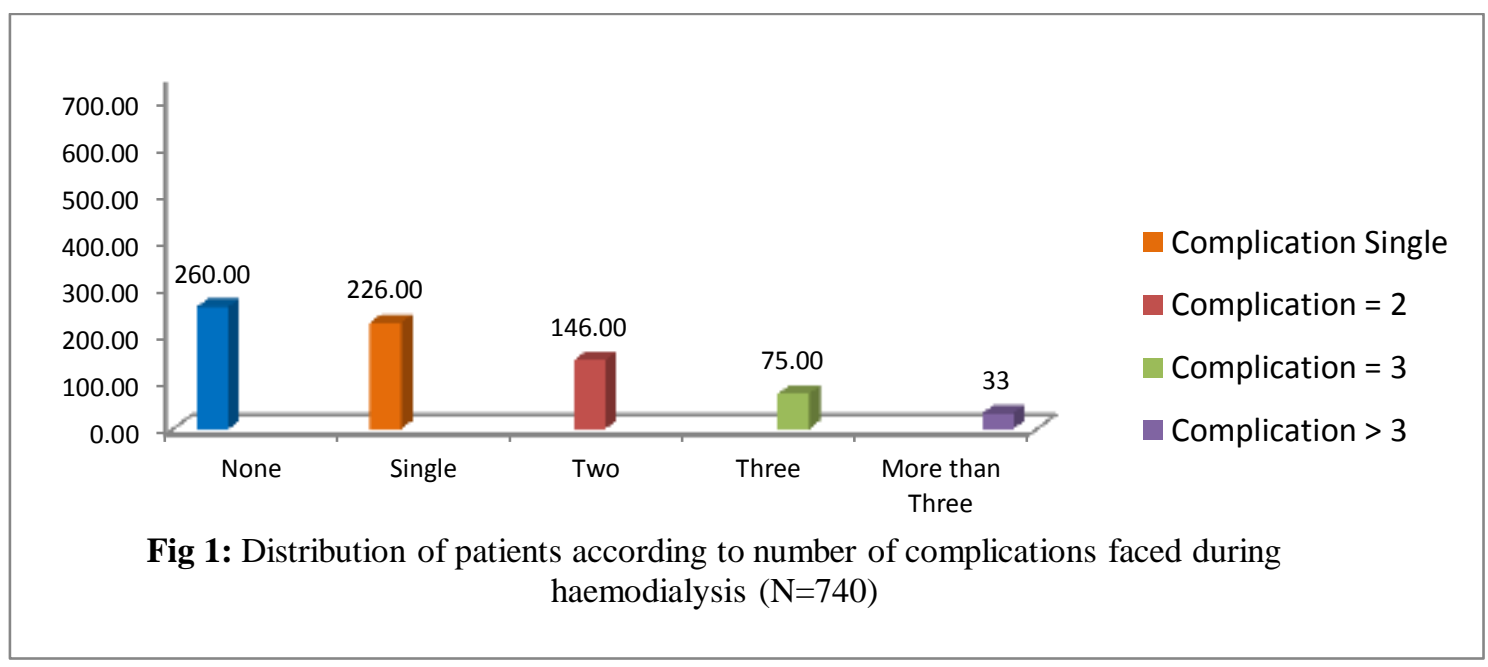

Out of 740 patients, $480(64.8 \%)$ patients developed some complication during the procedure. Maximum complications were patient related. Total of 466 (97\%) patients developed patient related complication (Fig 2) out of which Hypotension was the most frequent complication developed in $26.8 \%(\mathrm{~N}=125)$ of subjects. The frequency of vascular access-related complications (4.4\%) (Fig 3) and technical complications (3.1\%) (Fig 4) was very low. The frequency of other complications is mentioned in Table 1. Many patients developed more than one complication. $472(98.3 \%)$ patients had both patient-related as well as technical complications, $476(99.1 \%)$ developed patientrelated and vascular access-related complications, and 30 (6.25\%) patients had technical as well as vascular accessrelated complications. Four $(0.83 \%)$ patients developed complications belonging to all the three groups. 


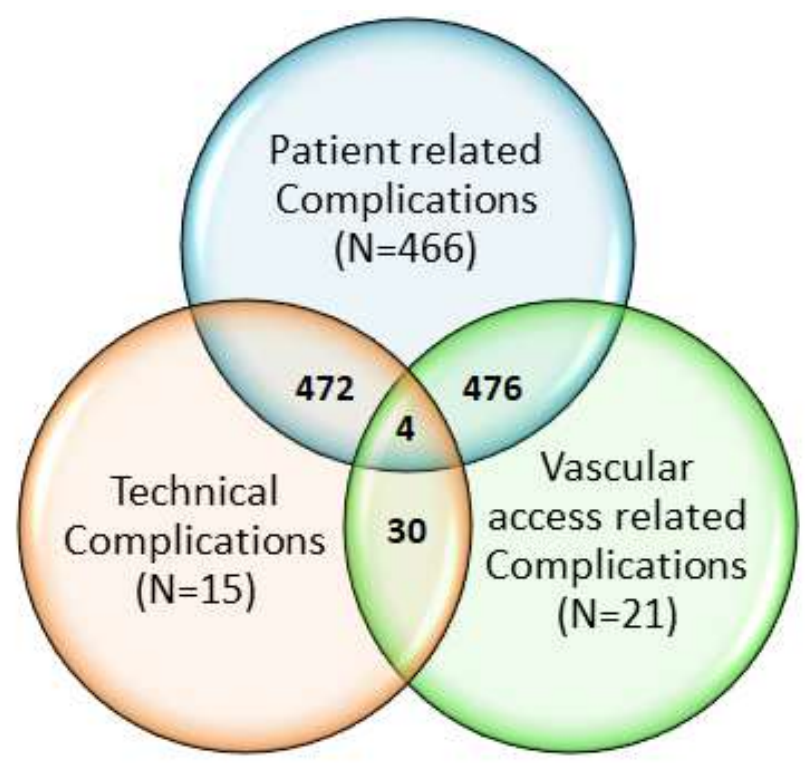

Fig 2:- Basic Venn diagram showing distribution of complications during hemodialysis

Table 1:- Group wise distribution of complications

\begin{tabular}{|c|c|c|c|c|c|}
\hline $\begin{array}{l}\text { Group 1 }(\mathrm{N}=466) \\
\text { Patient-related } \\
\text { Complications }\end{array}$ & $\%$ & $\begin{array}{l}\text { Group } 2(\mathrm{~N}=15) \\
\text { Technical Complication }\end{array}$ & $\%$ & $\begin{array}{l}\text { Group } 3(\mathrm{~N}=20) \\
\text { Vascular access-related } \\
\text { Complications }\end{array}$ & $\%$ \\
\hline $\begin{array}{l}\text { 1. Hypotension }(<80 \mathrm{~mm} \\
\text { of } \mathrm{Hg})\end{array}$ & $\begin{array}{l}26.8 \\
(\mathrm{~N}=125)\end{array}$ & $\begin{array}{l}\text { 1. Heparin-induced } \\
\text { thrombocytopenia }\end{array}$ & 0.0 & 1. AV Fistula induced & \\
\hline 2. $\begin{array}{l}\text { Hypertension } \\
\text { mm of } \mathrm{Hg})\end{array}$ & $\begin{array}{l}24.7 \\
(\mathrm{~N}=115)\end{array}$ & 2. Bleeding diathesis & 0.0 & $\begin{array}{ll}\text { A. } & \text { Arterio-Venous } \\
\text { Stenosis }\end{array}$ & 0.0 \\
\hline 3. Nausea & $\begin{array}{l}8.6 \\
(\mathrm{~N}=40)\end{array}$ & 3. Hemolysis & 0.0 & B. Thrombosis & $\begin{array}{l}20 \\
(\mathrm{~N}=4)\end{array}$ \\
\hline 4. Vomiting & $\begin{array}{l}19.5 \\
(\mathrm{~N}=91)\end{array}$ & 4. Neutropenia & 0.0 & C. Aneurysm & 0.0 \\
\hline 5. Muscle cramp & $\begin{array}{l}5.5 \\
(\mathrm{~N}=26)\end{array}$ & 5. Power failure & 0.0 & $\begin{array}{l}\text { D. Low dialysis } \\
\text { blood flow }\end{array}$ & $\begin{array}{l}60 \\
(\mathrm{~N}=12)\end{array}$ \\
\hline 6. Itching & $\begin{array}{l}5.6 \\
(\mathrm{~N}=27)\end{array}$ & 6. Air embolism & 0.0 & $\begin{array}{l}\text { E. High flow rate in } \\
\text { fistula }\end{array}$ & 0.0 \\
\hline 7. Fever $\left(>38^{\circ} \mathrm{C}\right)$ & $\begin{array}{l}5.6 \\
(\mathrm{~N}=27)\end{array}$ & 7. Exsanguinations & 0.0 & F. Steal Syndrome & \\
\hline 8. $\quad$ Chills/Shivering & $\begin{array}{l}11.2 \\
(\mathrm{~N}=52)\end{array}$ & 8. Blood clots in dialyzer & $\begin{array}{l}73.3 \\
(\mathrm{~N}=11)\end{array}$ & a) Pain & 0.0 \\
\hline 9. Headache & $\begin{array}{l}25.1 \\
(\mathrm{~N}=117)\end{array}$ & 9. Electrolyte disorder & 0.0 & b) Pallor & 0.0 \\
\hline 10. Chest pain & $\begin{array}{l}1.3 \\
(\mathrm{~N}=27)\end{array}$ & 10. Dialyzer reaction & & c) Necrosis & 0.0 \\
\hline 11. Pericarditis & 0.0 & $\begin{array}{l}\text { A. Type A immediate } \\
\text { Anaphylactic } \\
\text { reaction }\end{array}$ & $\begin{array}{l}26.7 \\
(\mathrm{~N}=4)\end{array}$ & $\begin{array}{l}\text { d) Diminished } \\
\text { Plus }\end{array}$ & 0.0 \\
\hline 12. Cardiac arrhythmia & 0.0 & $\begin{array}{l}\text { B. Type B after 15-30 } \\
\text { minutes }\end{array}$ & $\begin{array}{l}13.4 \\
(\mathrm{~N}=2)\end{array}$ & $\begin{array}{l}\text { 2. Develop during } \\
\text { catheter placing }\end{array}$ & \\
\hline 13. Myocardial infarction & 0.0 & & & $\begin{array}{l}\text { a) } \text { Cardiac } \\
\text { Arrhythmia }\end{array}$ & 0.0 \\
\hline 14. Sudden cardiac death & 0.0 & & & b) Pneumothorax & 0.0 \\
\hline 15. Cerebral Hemorrhage & 0.0 & & & 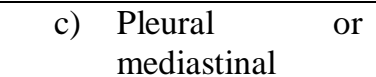 & 0.0 \\
\hline
\end{tabular}




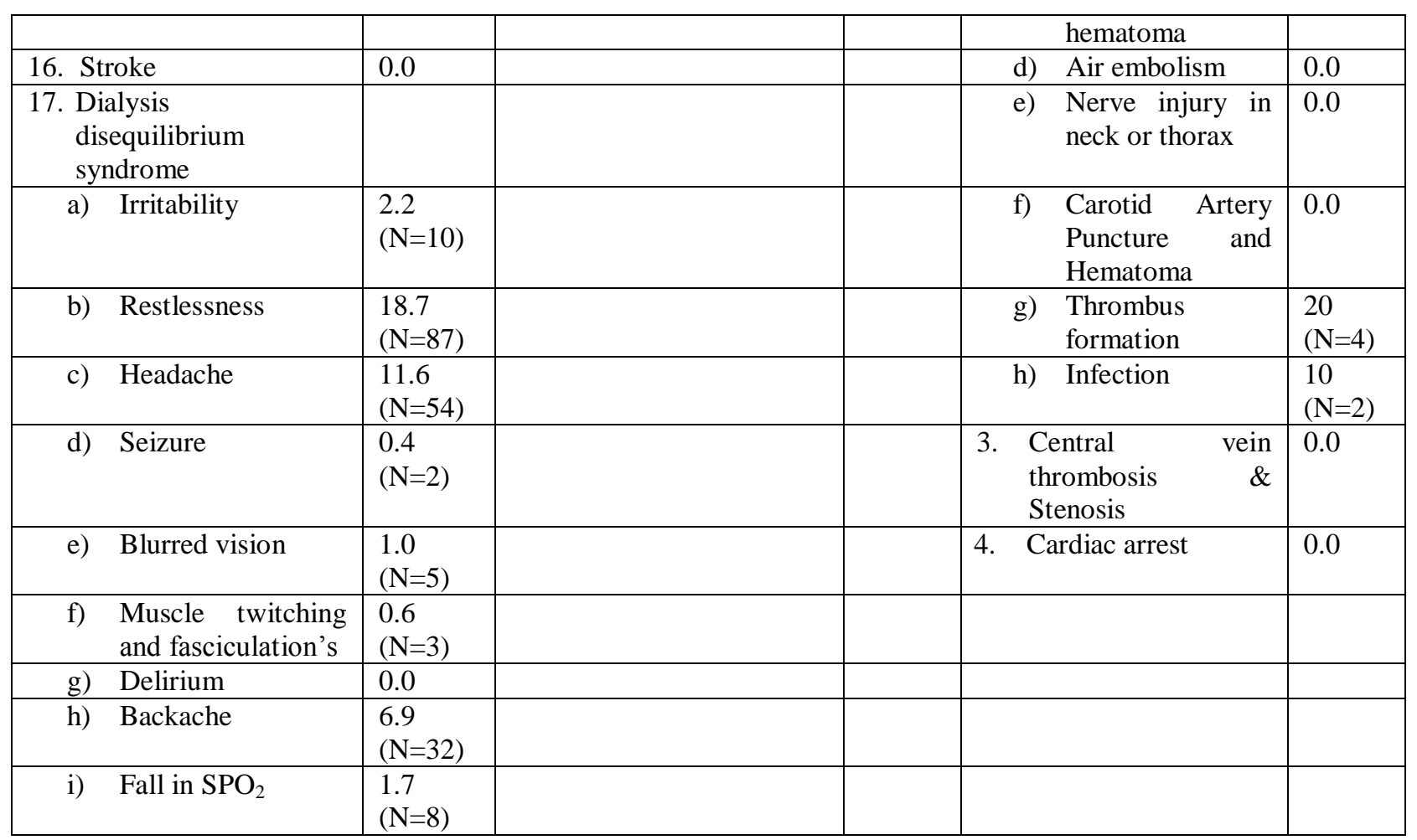

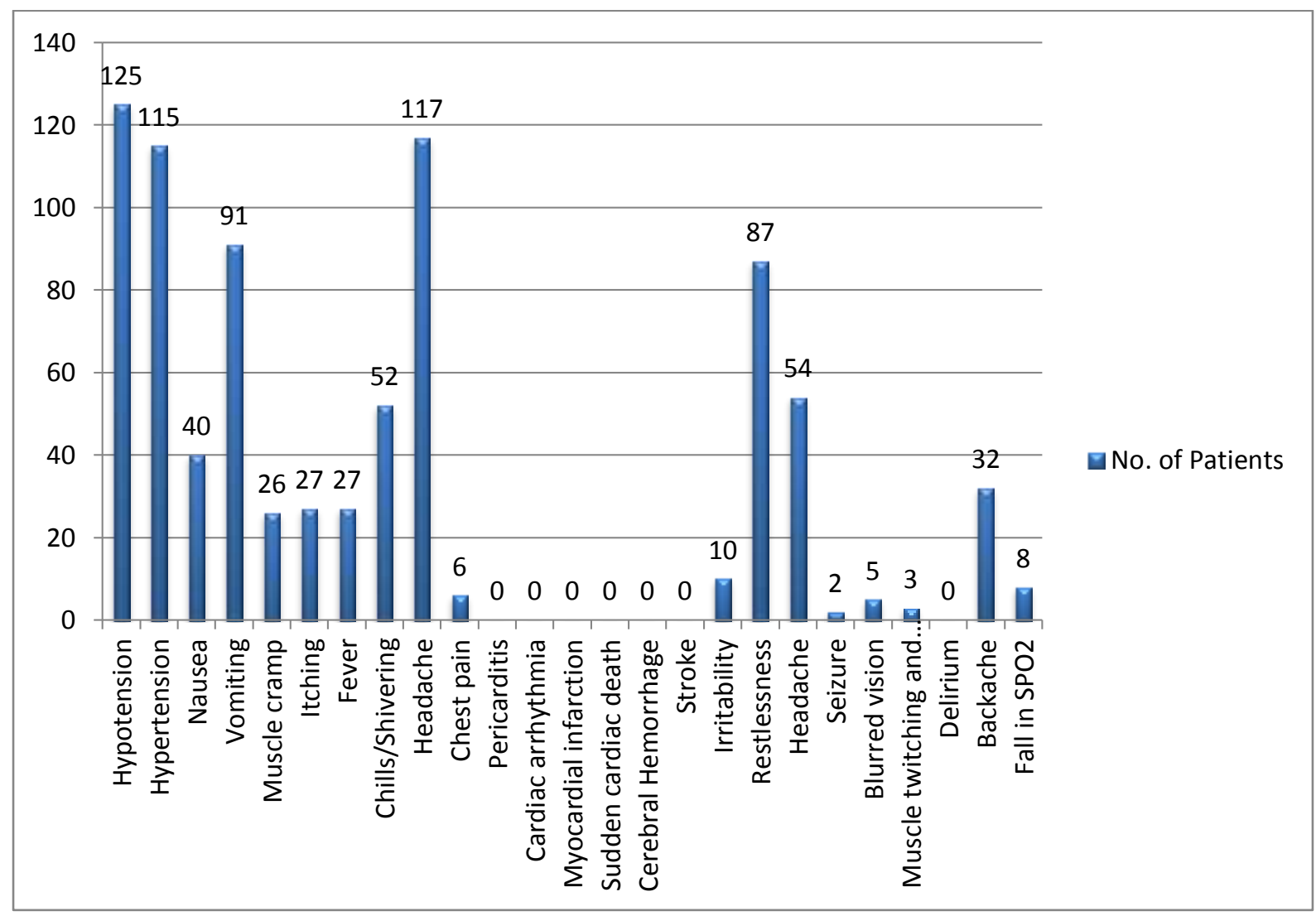

Fig 2:- Graph showing the distribution of patient-related complications ( $\mathrm{N}=466)$. 


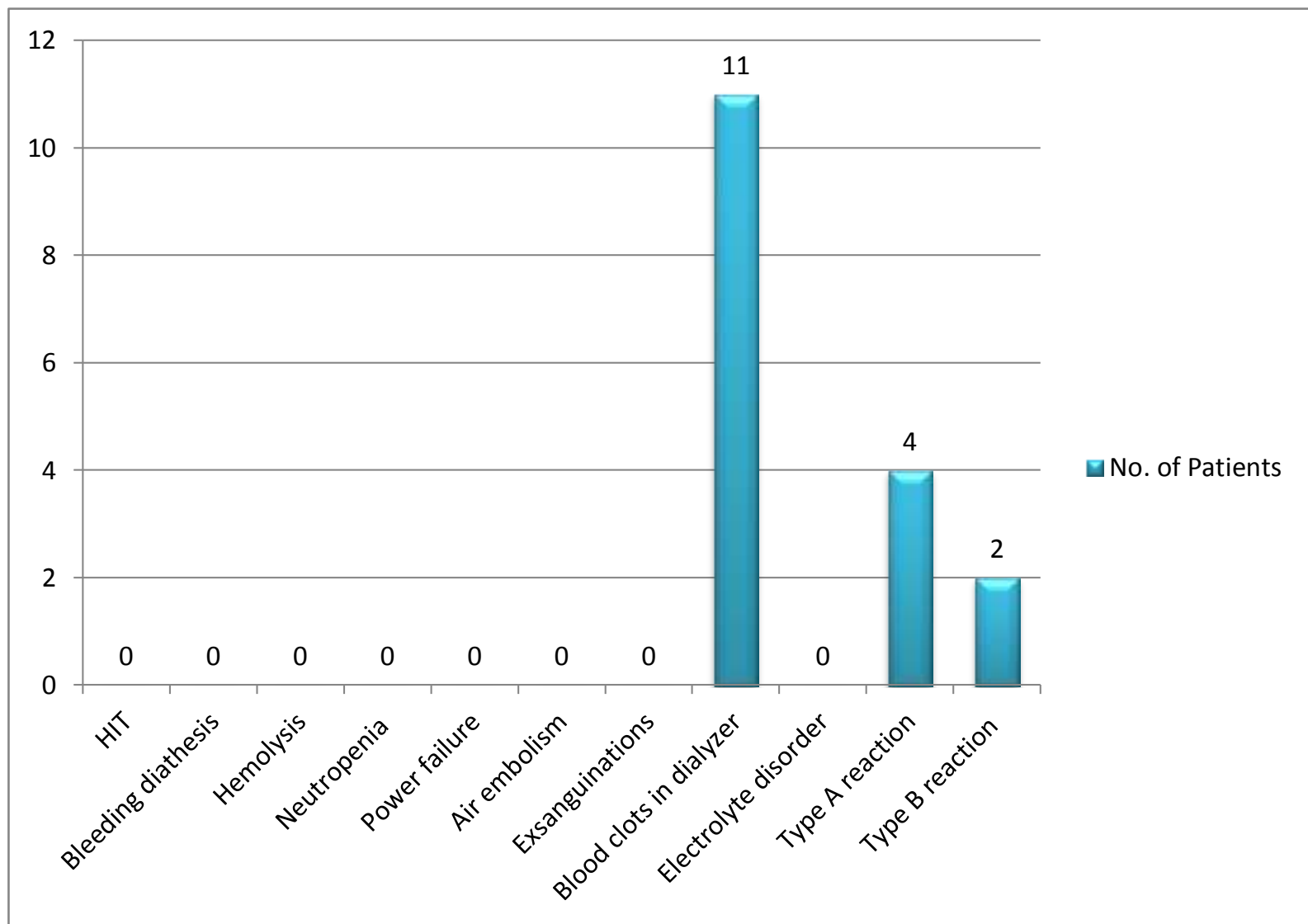

Fig 3:- Graph showing the distribution of technical complications $(\mathrm{N}=15)$.

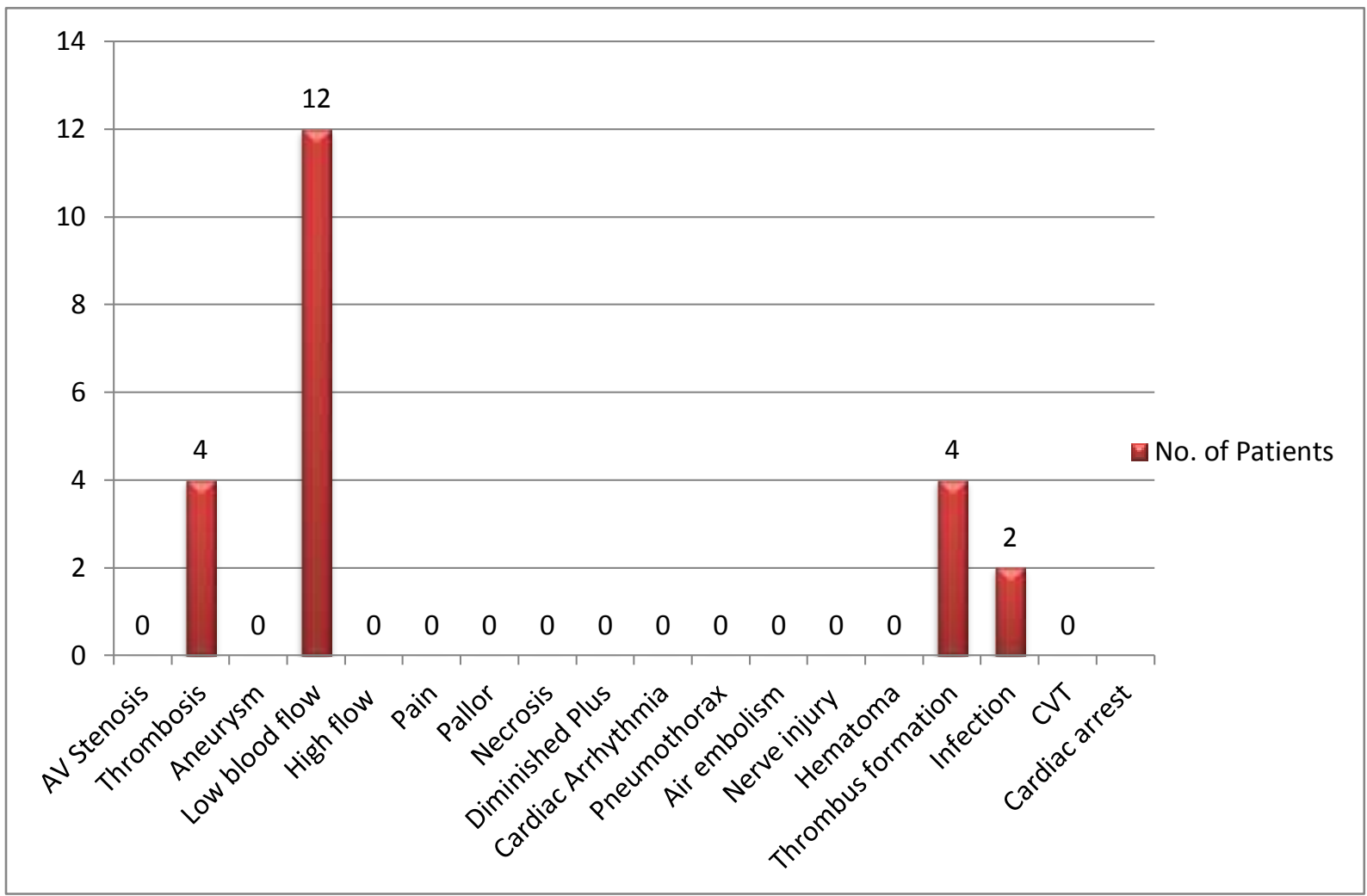

Fig 4:- Graph showing distribution of Vascular access-related complications $(\mathrm{N}=20)$ 


\section{Discussion:-}

Increased frequency and severity of hypotension, muscle cramps, headache, and the dialysis disequilibrium syndrome is observed these days because of faster and more aggressive UF with shorter dialysis times. To counteract this, dialysate sodium concentration can be increased. This could be achieved by maintaining higher sodium dialysate concentration for the entire duration of hemodialysis, infusions of $0.9 \%$ saline or hypertonic saline, or altering the dialysate $\mathrm{Na}$ concentration over the course of the hemodialysis session ( $\mathrm{Na}$ modeling). Ideally, the changes in plasma sodium should be limited to $4-5 \mathrm{mEq} / \mathrm{L}$.(Golper et al., 2014) The potential benefits include a reduced incidence of dialysis disequilibrium, vascular instability, and muscle cramps.

The incidence of hypotension in the dialysis population ranges between $15 \%$ and $30 \%$, being more common in women and the elderly.(Phoon, 2012) In our study most common complication encountered was the hypotensive episode which may be directly related to decreasing blood volume or to a decrease in cardiovascular activation as a response to the decreased cardiac filling. Hypotension results when the rate of intravascular volume removal exceeds its rate of refilling, especially if total peripheral resistance cannot compensate for the loss of intravascular volume.(Nette et al., 2005) Diabetic nephropathy is another cause of hypotension or risk factor for hypotension in patients undergoing hemodialysis.(Flynn III, 1996)

Intradialytic hypertension is the third most common complications which occur during hemodialysis procedure has been recognized for many years.(Levin, 1993) In our study, $24.7 \%$ had intradialytic hypertension.

In the study of Chang \& Tan, it is clearly stated that nausea and vomiting are common complications during hemodialysis, an incidence of nausea and vomiting are reported as $18.2 \%$ and $9.8 \%$ respectively,(Chong \& Tan, 2013) the occurrence of nausea and vomiting is mainly due to rapid fall of blood pressure and urea during hemodialysis.

The headache came to be second most frequent complications which may be caused due to shifting of the large amount of water and electrolytes during hemodialysis procedure. the commonest feature of a headache which was observed are frontotemporal in location, moderate in severity, pain is of short duration $<4$ hours and of throbbing type.(Göksan, Karaali-Savrun, Ertan, \& Savrun, 2004) Muscle cramps occur in as many as $20 \%$ of dialysis treatments but our study recorded only 5.5\%. Although their pathogenesis is uncertain, cramps are known to be more frequent when UFRs are high and when low Na dialysate is employed, suggesting a volume related etiology.(Golper et al., 2014)

Patients with ESRD frequently have left ventricular hypertrophy, coronary artery and pericardial disease, and valvular sclerosis.(Singh et al., 2014) In our study, 27 patients experienced chest pain during hemodialysis although no mortality was seen. The conduction system may be affected by calcific deposits particularly in patients with the adynamic bone disease. Superimposed upon these pathologies are the rapid changes in electrolyte concentrations inherent in the hemodialysis. It is not surprising that hemodialysis may provoke cardiac arrhythmias.

\section{Conclusions:-}

Hemodialysis is associated with a vivid number of complications some are even life-threatening, however strict monitoring proper assessment of patients and good clinical acumen may help in early detection and early management without the termination of life-saving procedures. Longer, slower dialysis treatments and shorter, more frequent dialysis treatments make possible removal of larger amounts of fluid during the week without the patient experiencing as much hypotension and cramping. 


\section{Reference:-}

1. Arroyo, R. A. (2008). Electrolyte and acid-base balance disorders in advanced chronic kidney disease . Nefrologia, 28(SUPPL. 3), 87-93. Retrieved from https://www.scopus.com/inward/record.uri?eid=2-s2.051349169415\&partnerID=40\&md5=7b6704e289aadb8b4251638b6c05e504

2. Chong, V. H., \& Tan, J. (2013). Prevalence of gastrointestinal and psychosomatic symptoms among Asian patients undergoing regular hemodialysis. Nephrology, 18(2), 97-103. https://doi.org/10.1111/nep.12000

3. Davenport, A. (2006). Intradialytic complications during hemodialysis. Hemodialysis International, 10(2), 162167. https://doi.org/10.1111/j.1542-4758.2006.00088.x

4. Flynn III, J. J. (1996). Factors contributing to hypotension during hemodialysis. Geriatric Nephrology and Urology January, 6(2), 99-104.

5. Göksan, B., Karaali-Savrun, F., Ertan, S., \& Savrun, M. (2004). Haemodialysis-related headache. Cephalalgia, 24(4), 284-287. https://doi.org/10.1111/j.1468-2982.2004.00668.x

6. Golper, T. A., Fissell, R., Fissell, W. H., Hartle, P. M., Sanders, M. L., \& Schulman, G. (2014). Core Curriculum in Dialysis 2013 Update, 63(1), 153-163. https://doi.org/10.1053/j.ajkd.2013.07.028.Core

7. Levin, N. W. (1993). INTRADIALYTIC HYPERTENSION. Seminars in Dialysis, 6(6), 370-371.

8. Nette, R. W., van den Dorpel, M. A., Krepel, H. P., Ie, E. H. Y., van den Meiracker, A. H., Poldermans, D., ... Zietse, R. (2005). Hypotension during hemodialysis results from an impairment of arteriolar tone and left ventricular function. Clinical Nephrology, 63(4), 276-83. Retrieved from http://www.ncbi.nlm.nih.gov/pubmed/15847254

9. Phoon, R. K. (2012). Chronic kidney disease in the elderly - Assessment and management. Australian Family Physician, 41(5), 940-944. https://doi.org/10.2217/cpr.14.46

10. Prabhakar, Singh, R. G., Singh, S., Rathore, S. S., \& Choudhary, T. A. (2015). Spectrum of intradialytic complications during hemodialysis and its management: a single-center experience. Saudi Journal of Kidney Diseases and Transplantation, 26(1), 168-72. https://doi.org/10.4103/1319-2442.148771

11. Singh, S., Doley, P., Pragya, P., Sivasankar, M., Singh, V., \& Singh, N. (2014). Echocardiographic Changes in Patients with ESRD on Maintenance Hemodialysis-A Single Centre Study. J Cardiovasc Dis Diagn, 2(4), 2-5. https://doi.org/10.4172/2329-9517.1000165 